\title{
Yığma Yapılarda Patlama Etkilerinin İncelenmesi
}

\author{
${ }^{* 1}$ Elif Toplu and ${ }^{2}$ Osman Kirtel \\ ${ }^{*}$ Sakarya Uygulamalı Bilimler Üniversitesi, İnşaat Mühendisliği / Teknoloji Fakültesi, Sakarya, Türkiye \\ ${ }^{2}$ Sakarya Uygulamalı Bilimler Üniversitesi, İnşaat Mühendisliği / Teknoloji Fakültesi, Sakarya, Türkiye
}

\section{Özet}

Patlama ve deprem etkileri zamana bağlı bir davranış göstermekte ve yapı üzerinde farklı etkilere neden olabilmektedir. Ülkemizde yığma türü yapıların kullanımı oldukça yaygındır. Ülkemizde birçok yapı çeşitli nedenlerle kimi zaman iş kazaları sonucunda kimi zaman da terör kaynaklı patlama etkilerine maruz kalabilmektedir. Patlama yüklerinin tahmini ile ilgili nümerik çalışmalara literatürde rastlanılması ile birlikte patlama etkilerinin gelişi güzel ve ağır etkileri geçmişte yaşanan tecrübelerden elde edilen veriler ışığında patlama etkilerinin tahmininde kullanılmasına olanak sağlamıştır. Bu çalışmada yığma türü bir yapının patlama etkileri altında zaman tanım alanında analizi gerçekleştirilmiştir. Patlama etkileri ile ilgili tahmin yürütülmüş ve yapı üzerinde oluşan etkiler değerlendirilmiş̧ir. Çalışma sonucunda nümerik analiz sonuçlarının tahmini verilerle örtüştüğü gözlenmiştir.

Anahtar kelimeler: Patlama etkisi, yığma yapılar, zaman tanım alanında analiz

\begin{abstract}
Explosion and earthquake effects show a time-dependent behavior and may cause different effects on the building. The use of masonry type structures is quite common in our country. Many buildings in our country are exposed to explosion effects, sometimes as a result of occupational accidents and sometimes due to terrorism for various reasons. Numerical studies on the estimation of explosion loads have been encountered in the literature, and the random and severe effects of the explosion effects have enabled them to be used in the prediction of the explosion effects in the light of the data obtained from the past experiences. In this study, a masonry type structure was analyzed in the time domain under explosion effects. It was observed that the numerical analysis results obtained from the study coincided with the estimated data.
\end{abstract}

Keywords: Explosion effect, masonry structures, time-history analysis 


\section{Giriş}

Patlamaya dayanıklı yapı tasarımında çoğunlukla yüksek kesme kapasitesine sahip betonarme elemanlar kullanılmaktadır. Bir patlama olayında yapı üzerinde öncelikli olarak en zayıf elemanlarda hasar meydana gelmektedir. Camların kırılması, duvar göçükleri ve sonrasında taşıyıcı sistemde hasarlar oluşmaktadır. Yı̆̆ma yapılarda ise taşıyıcı sistemde görev alan duvarlar patlama etkilerinde yapı taşıyıı sistemini etkileyebilmektedir [1].

Patlama olaylarında meydana gelen basınç etkileri çevre yapıları kuşatmakta ve etkisini oldukça geniş bir alana yayabilme kapasitesine sahiptir. Şekil 1' de yakın zamanda gerçekleşen ve çevresindeki yapıları etkilemiş olan patlama örnekleri verilmiştir:

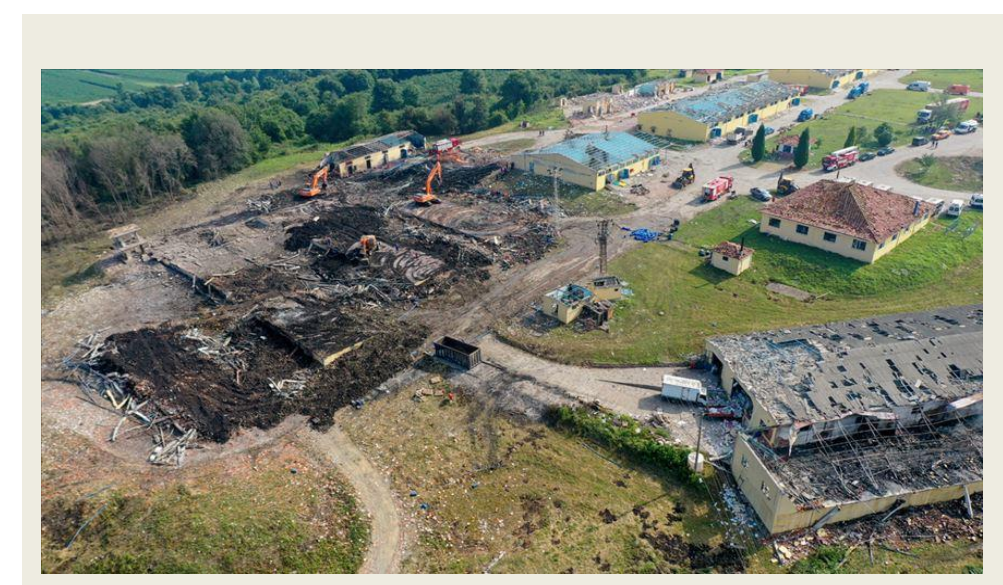

a) Sakarya'da bir havai fişek fabrikasında gerçekleşen patlama, 2020 [2].

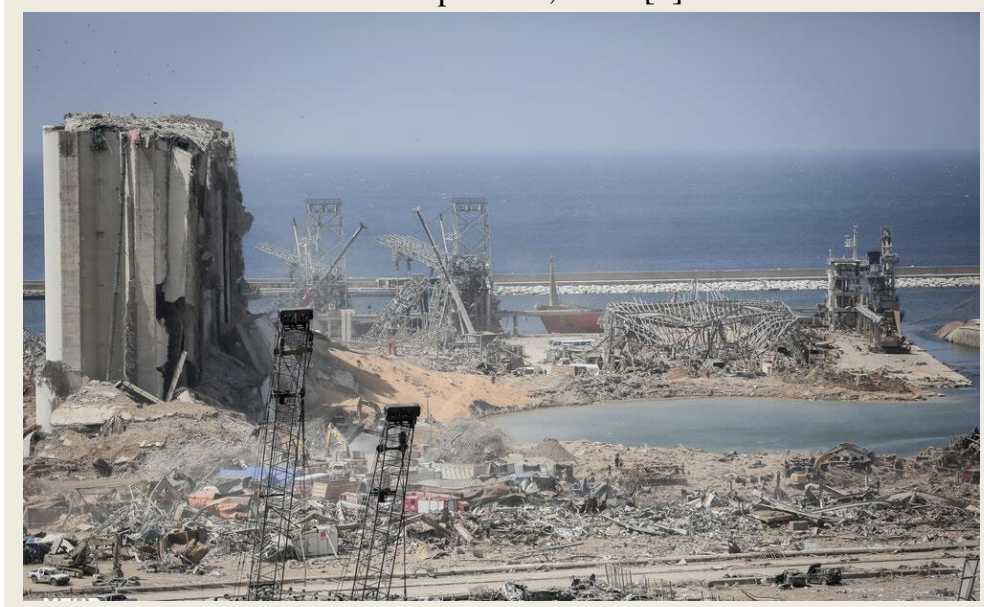

b) Beyrut patlamas1, $2020[3]$.

Şekil 1. Patlama örnekleri 
Patlama etkileri tahmin edilmesinde, tehlikeli ve maliyetli olması bakımından deneysel çalışmalar sınırlı seviyede ve ölçekli yapılarda yapılmaktadır. Patlama ölçeği denilen "hopkinson cranz" yasasına göre patlayıcı ağırlığı ve patlayıcının gücünün hesaba katıldığı ölçekli mesafeler patlama basıncı hesaplamalarında kullanılmaktadır [4]

Wang W. ve diğ., (2012)[5], Liu Y. Ve diğ., (2018) [6], Gram M. Ve diğ., (2012)[7], Fujikura ve diğ. (2008)[8], Maji A. K.[9], ASCE F. ve diğ. (2010)[10], Rey V. ve diğ. (2018)[11], ölçeklendirme kanunlarından yararlanmış ve patlama fonksiyonlarından yaralanmış deneysel çalışmalarda bulunmuştur. Patlama basınçlarının ölçümünde çeşitli şok dalgası ölçüm cihazları basınçölçerler ve yüzey mikrofonu olarak adlandırılan duvar yüzeyindeki gerilmeleri ölçen cihazlar kullanılmıştır (Şekil 2).
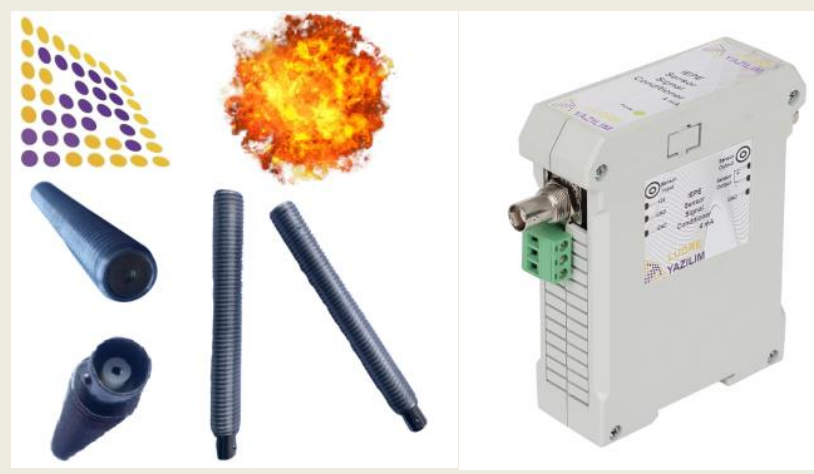

a) IEPE Koşullayıcı ve sok dalgası ölçüm cihazı

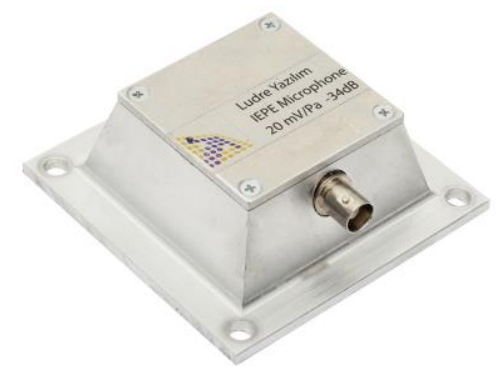

b) Yüzey mikrofonu

Şekil 2. Patlama hava basıncı ve yüzey basıncı ölçüm cihazları [12].

Patlama olayları gelişigüzel yüklemeler olması sebebiyle yapı üzerindeki etkileri ancak gerçekleşmiş patlama olayları (Şekil 3) referans alınarak etkileri ölçülmüş ya da deneysel yöntemlere başvurulmuştur. 


\begin{tabular}{|c|l|}
\hline $\begin{array}{l}\text { Basınç } \\
(\mathrm{kPa})\end{array}$ & Hasar \\
\hline 0.15 & Rahatsız edici ses \\
\hline 0.20 & $\begin{array}{l}\text { Önceden hasarı büyük camların } \\
\text { kııılması }\end{array}$ \\
\hline 0.30 & Yükses ses \\
\hline 0.70 & $\begin{array}{l}\text { Önceden hasarı küçük camların } \\
\text { kıııması }\end{array}$ \\
\hline 1.0 & Tipik cam kırılması \\
\hline 2.0 & Asma tavan hasarı \\
\hline 3.0 & Küçük ölçekli yapısal hasar \\
\hline $3.5-7.0$ & $\begin{array}{l}\text { Küçük ve büyük pencerelerin } \\
\text { patlaması, bazı pencere } \\
\text { çerçevelerinin hasarı }\end{array}$ \\
\hline 5.0 & $\begin{array}{l}\text { Zayıf yapılarda küçük ölçekli hasar. } \\
\text { Çatı kiremitlerinin uçması. }\end{array}$ \\
\hline 7.0 & Zayıf yapılarda önemli hasar \\
\hline
\end{tabular}

\begin{tabular}{|c|l|}
\hline $\begin{array}{l}\text { Basınç } \\
(\mathrm{kPa})\end{array}$ & Hasar \\
\hline 35 & $\begin{array}{l}\text { Ağaç telefon/elektrik direklerinin } \\
\text { hasarı }\end{array}$ \\
\hline 50 & Tren vagonlarının devrilmesi \\
\hline $50-55$ & Hafif tuğla duvarların hasarı \\
\hline $50-65$ & Çelik çerçeveli yapıların göçmesi \\
\hline $50-70$ & Otomobillerin ciddi oranda ezilmesi \\
\hline $55-70$ & $\begin{array}{l}\text { Hafif tuğla duvarların tamamen } \\
\text { göçmesi }\end{array}$ \\
\hline 65 & $\begin{array}{l}\text { Çelik uzay kafes çelik köprülerin } \\
\text { göçmesi }\end{array}$ \\
\hline$>70$ & $\begin{array}{l}\text { Betonarme olmayan tüm yapıların } \\
\text { göçmesi }\end{array}$ \\
\hline 90 & $\begin{array}{l}\text { Ağır tuğla / taş duvarların tamamen } \\
\text { göçmesi }\end{array}$ \\
\hline 490 & $\begin{array}{l}\text { Ağır yığma yapıların, betonarme yapı } \\
\text { ve köprülerin göçmesi }\end{array}$ \\
\hline
\end{tabular}

* 2.Dünya Savaşı Verileri

Şekil 3. II. Dünya savaşı patlama verileri [13].

Amerika Birleşik Devletleri Federal Acil Durum Yönetim Kurumu patlama basıncının yapı üzerindeki etkilerine yönelik hazırladığı bir raporda (FEMA 427) patlama basıncının binalarda oluşturacağı tahmini hasarları bir tabloda bir araya getirmiştir (Tablo 1).

Tablo 1. Patlama basıncının binalarda oluşturacağı tahmini hasarlar [14].

\begin{tabular}{ll}
\hline Basınç Değeri $(\mathrm{kPa})$ & Binada Meydana Gelen Hasar \\
\hline $1.03-1.52$ & Camların kırılması \\
$3.45-7.58$ & Bina dış yüzeylerinde ufak hasarlar \\
$7.58-12.41$ & Metal panel ve kaplamalarda bükülmeler \\
$\mathbf{1 2 . 4 1}-\mathbf{2 0}$ & Beton bloklarda ve duvarlarda yıkılmalar \\
$34.48+$ & Ahşap çerçeveli binalar çökmesi \\
$27.58-48.26$ & Çelik çerçeveli binalarda ciddi hasar \\
$41.37-62.06$ & Güçlendirilmiş beton yapılarda ciddi hasar \\
$68.95-82.74$ & Yapıların tamamen yıkılması \\
\hline
\end{tabular}

\section{Malzeme ve Yöntem}

Patlama yüklerinin tasarımı çeşitli kabullere yol açmış ve bu kabullerden yola çıkılarak nümerik çalışmalar yapılmıştır. Bu çalışma da Hopkinson-Cranz Yasası olarak adlandırılan patlama ölçeği kullanılmıştır. Patlamada ölçekli mesafe, gerçek mesafe ve patlayıcı ağırlığı dikkate alınarak aynı zamanda patlayıcının türü ve patlama ısısının ölçek olarak kullanıldığı mesafeyi ifade etmektedir [15]. 
Patlamada yapıların alacağı hasarlar tahmin edilmesi güç ve gelişigüzel olabilmektedir. Geçmişte yaşanan olaylardan edinilen tecrübeler ve elde edilmiş birtakım deneysel çalışmalar sonucunda basınç etkilerine göre yapı üzerindeki hasarlar hakkında bilgi edilebilmektedir. Bununla ilgili federal acil durum yönetmeliği patlama basınçlarını yapı üzerlerindeki etkileri sözel olarak ifade etmiştir. $\mathrm{Bu}$ çalışma kapsamında da bu basınç değerleri referans alınarak sayısal verilerle sonuçların desteklenmesi amaçlanmaktadır.

\section{Sayısal Çalışma}

Yı̆̆ma yapı türüne ait pencere ve kapı boşluk boyutlar ve malzeme özellikleri TBDY 2018'e göre tasarlanmıştır. $10 \mathrm{~kg}$ lık bir patlayıcının 10 metre mesafede patlaması sonucunda yapı üzerinde meydana gelen patlama basınçları ve patlama süreleri hesap edilmiştir. Yüklemeler sonlu elemanlar yöntemine dayalı SAP 2000 yazılımı kullanılarak dinamik bir darbe yükü şeklinde etki ettirilmiştir.

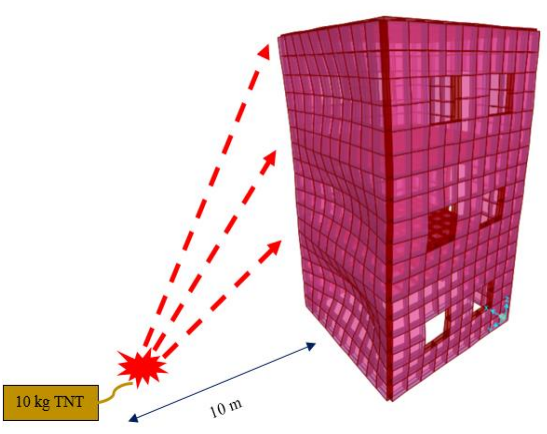

a) Yapı modeli ve patlama yönü

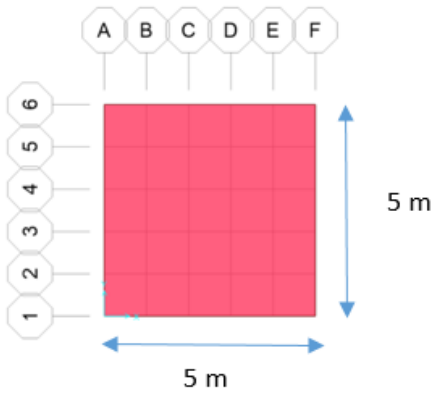

b) Yap1 en kesiti boyutları

Şekil 4. Yapı modeli.

Yapıya ait malzeme bilgileri Tablo 2'de kat seviyelerine etki eden patlama fonksiyonları ise Şekil 5 'te verilmiştir.

Tablo 2. Yığma duvar malzeme özellikleri [16]

\begin{tabular}{|c|c|c|c|c|c|}
\hline Malzeme Türü & $\begin{array}{l}\text { Elastisite modülü } \\
(\mathrm{MPa})\end{array}$ & Poisson oranı & $\begin{array}{c}\text { Birim hacim ağırlığ } 1 \\
\left(\mathrm{kN} / \mathrm{m}^{3}\right)\end{array}$ & $\mathrm{f}_{\mathrm{k}}(\mathrm{kPa})$ & $\mathrm{f}_{\mathrm{vk} 0}(\mathrm{kPa})$ \\
\hline Tuğla (M1-M2) & 1500 & 0.15 & 19 & 200 & 100 \\
\hline
\end{tabular}




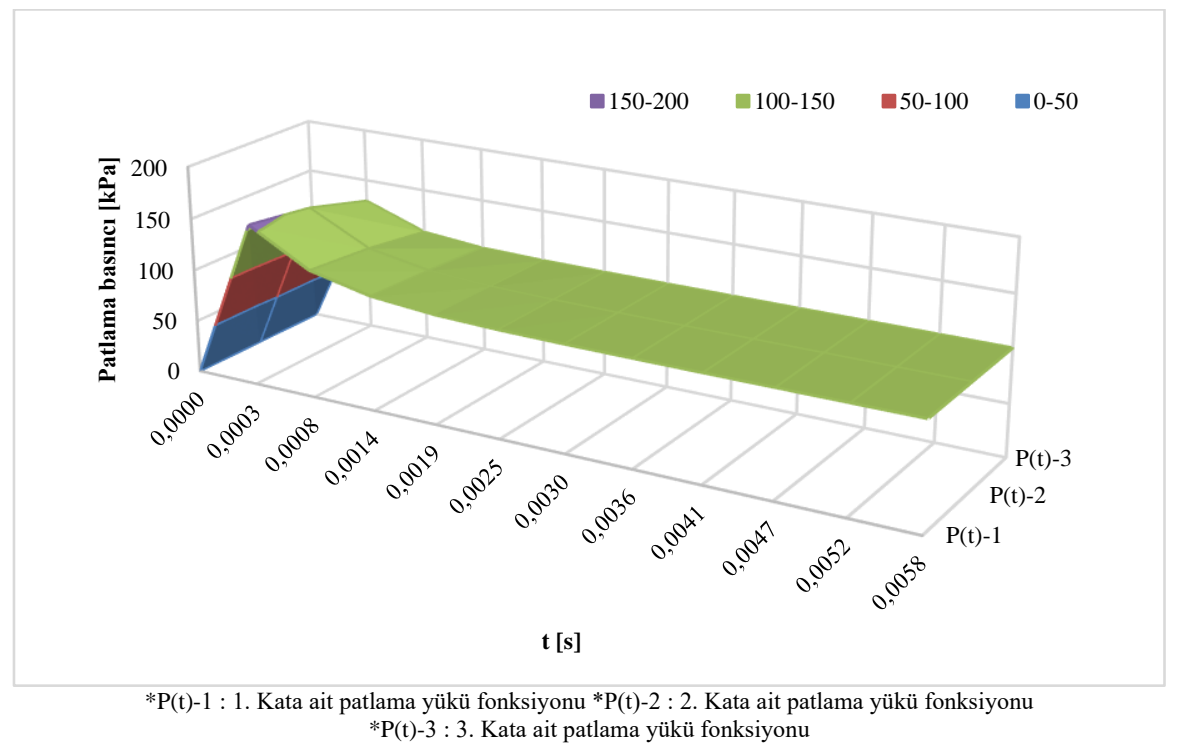

Şekil 5. Katlara etki eden patlama fonksiyonları.

\section{Sonuçlar}

Modal analiz sonucunda yapıda meydana gelen serbest titreşim modları Şekil 6'da verilmiştir:

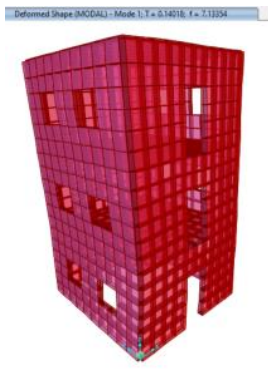

$\mathrm{T}=0.14 \mathrm{~s}$

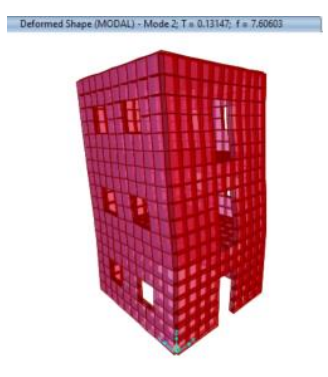

$\mathrm{T}=0.13 \mathrm{~s}$

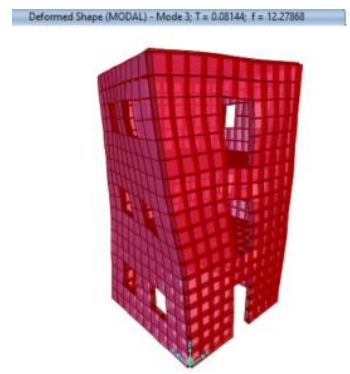

$\mathrm{T}=0.08 \mathrm{~s}$

Şekil 6. Yığma yapı serbest titreşim modları.

Patlama analizleri sonucunda yapıda meydana gelen zamana bağlı yer değiştirmeler kat köşeleri düğüm noktaları (Şekil 7) için Şekil 8'de verilmiştir: 


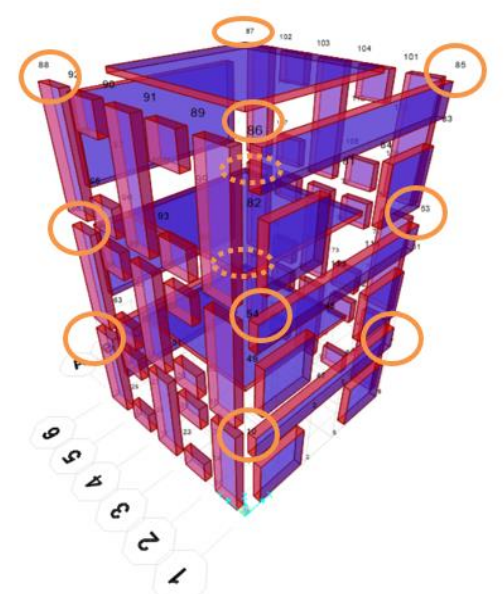

Şekil 7. Dügümm noktalarının gösterimi
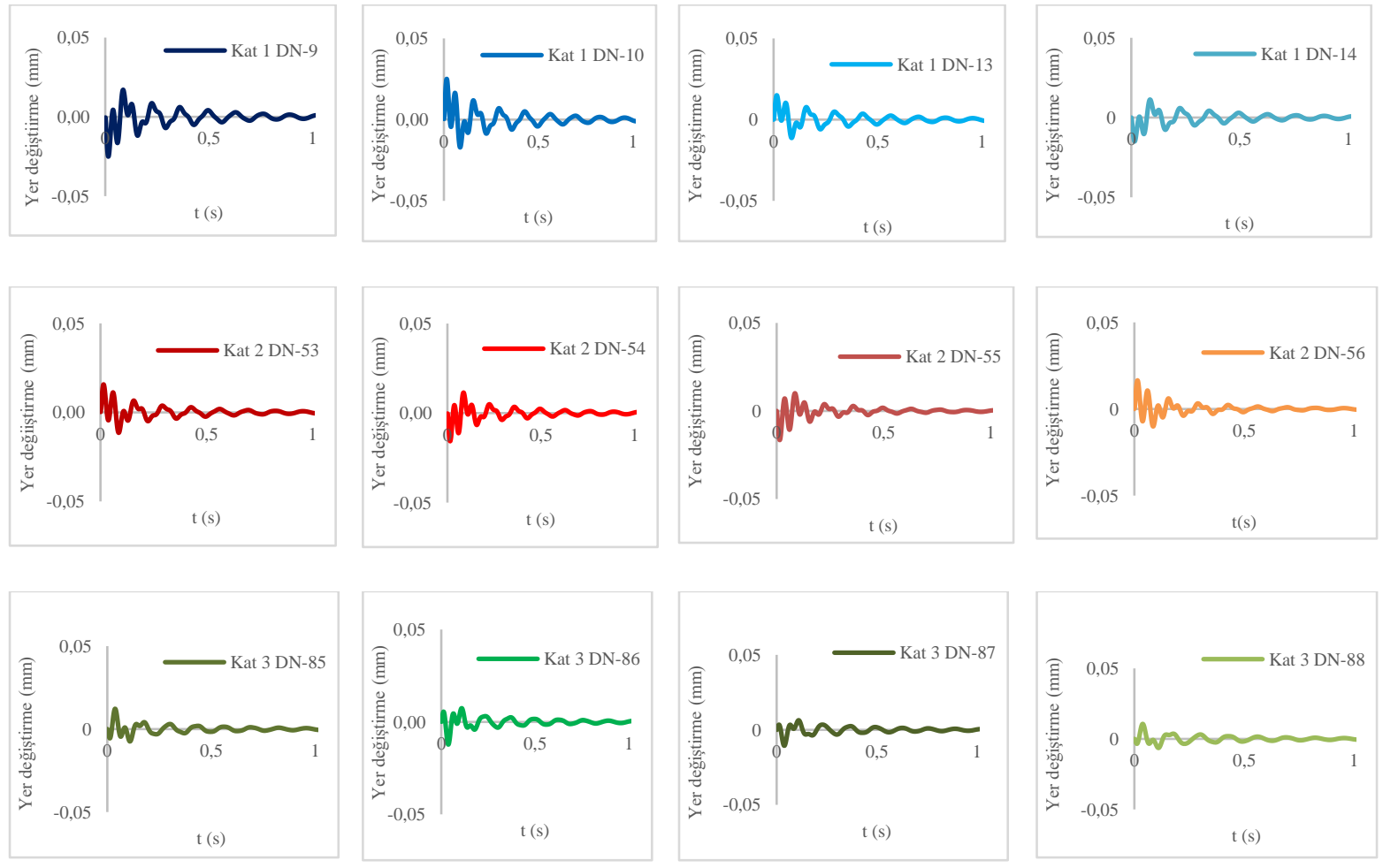

Şekil 8. Kat seviyelerinde köşe düğüm noktalarında meydana gelen zamana bağlı yer değiştirmeler [mm].

Patlama analizleri sonucunda yapıda meydana gelen yer değiştirme, maksimum kayma ve normal gerilmeler Şekil 9'da verilmiş olup Tablo 3'te sınır değerler ile karşılaştırılmıştır: 


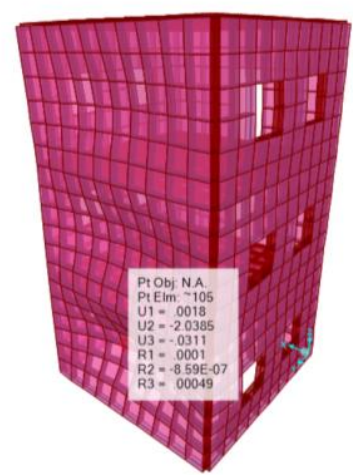

a) $\mathrm{t}=0.006 \mathrm{~s}$ için yer değiştirme $[\mathrm{mm}]$

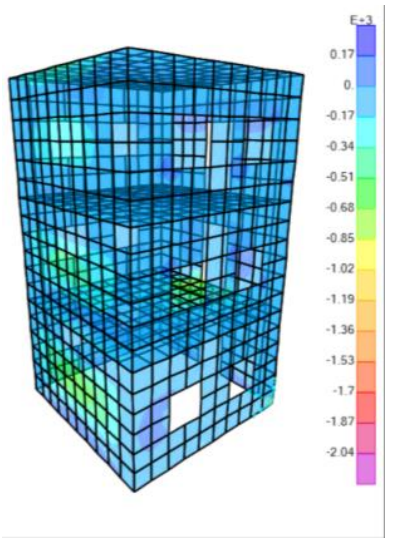

c) Maksimum basınç gerilmeleri $[\mathrm{kPa}]$

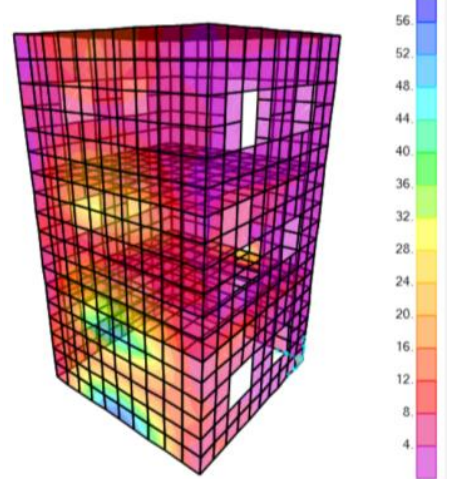

b) Maksimum kayma gerilmeleri $[\mathrm{kPa}]$

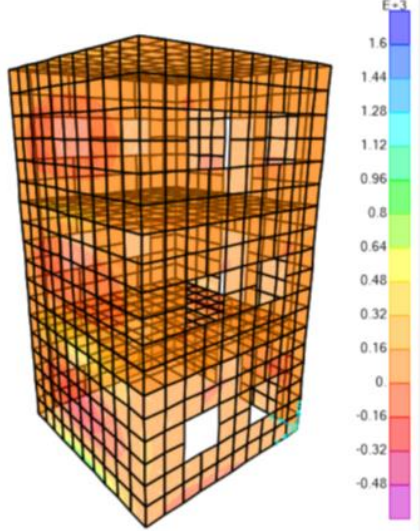

d) Maksimum çekme gerilmeleri $[\mathrm{kPa}]$

Şekil 9. Patlama analizi sonucu şekil değiştirme ve gerilmeler 
Tablo 3. Hasar durumlarının karşılaştırılması

\begin{tabular}{|c|c|c|c|c|c|}
\hline & $\begin{array}{l}\text { Sinır değerler } \\
\text { (TBDY 2018) }\end{array}$ & $\begin{array}{l}\text { Sinır değerler } \\
\text { (FEMA 427) }\end{array}$ & $\begin{array}{l}\text { Maksimum 1. ve } 2 . \\
\text { Kat arası maksimum } \\
\text { yer değiştirme için }\end{array}$ & $\begin{array}{c}\text { Maksimum } \\
\text { Gerimeler }\end{array}$ & Hasar durumu \\
\hline $\begin{array}{l}\text { Göreli kat ötelemesi } \\
\text { oranı }\end{array}$ & 0,007 & - & $8,33 \cdot 10^{-6}$ & - & $\begin{array}{c}\text { Göreli kat ötelemesi sınır } \\
\text { değerlerin altında }\end{array}$ \\
\hline $\begin{array}{l}\text { Maksimum kayma } \\
\text { gerilmeleri }\end{array}$ & $100 \mathrm{kPa}$ & - & - & $60 \mathrm{kPa}$ & $\begin{array}{l}\text { Duvarlarda kesme } \\
\text { kapasitesi aşılmadı }\end{array}$ \\
\hline $\begin{array}{l}\text { Maksimum basınç } \\
\text { gerilmeleri }\end{array}$ & $200 \mathrm{kPa}$ & $20 \mathrm{kPa}$ & - & $680 \mathrm{kPa}$ & $\begin{array}{c}\text { Duvarlarda basınç kapasitesi } \\
\text { aşıldı }\end{array}$ \\
\hline $\begin{array}{l}\text { Maksimum çekme } \\
\text { gerilmeleri }\end{array}$ & $200 \mathrm{kPa}$ & - & - & $320 \mathrm{kPa}$ & $\begin{array}{c}\text { Duvarlarda basınç kapasitesi } \\
\text { aşı1ldı }\end{array}$ \\
\hline
\end{tabular}

Çalışma sonucunda ortam basıncı hesaba katılmaksızın 0-50 kPa arasında bir yükleme yapılmıştır. 12.41 - 20 kPa seviyelerinde FEMA 427'ye göre duvarlarda yıkılmalar meydana gelmektedir. 50$70 \mathrm{kPa}$ seviyelerinde 2. Dünya savaşı verilerine göre hafif tuğla elemanlarının göçmesi beklenmektedir. Yapının dinamik davranışı ve yapı üzerindeki gerilmeler dikkate alındığında yapının 1. Katında yaklaşık 2 mm'lik yer değiştirme meydana gelmiştir. Duvarda meydana gelen gerilmeler dikkate alındı̆̆ında M1-M2 tuğla duvarları TBDY 2018'e göre 100 kPa'lık başlangıç kesme dayanımına sahiptir. Yapılar analizler sonucunda duvarların hasar aldığı ancak kesme kapasitesinin aşılmadı̆̆ görülmektedir.

\section{Tartışma ve Sonuç}

Yap1 üzerinde mesafelere bağlı olarak maksimum gerilmeler en alt katta oluşurken üst kata doğru gerilmeler azalmıştır. Yapılan nümerik çalışma sonucu tahmin edilen verilerle örtüşmektedir. Patlama etkilerine karşı yığma yapılar betonarme yapılara oranla daha çok etkilenmektedir. Yığma yapılarda duvarlar taşıyıcı sistem elemanı olarak görev yaparken betonarme yapılarda duvarlar taşıyıcı sistem elemanı değildir. Bu nedenle patlamaya maruz kalan yığma yapılarda duvarlar hasar aldığında yapı taşıyıcı sistemi de etkilenecektir. Betonarme yapılarda ise duvarların hasar alması yapı taşıyıcı sistemini etkilemeyecektir. Bu nedenle Tablo 1'deki veriler doğrultusunda patlama etkilerine karşı yapı tasarımında yüksek kesme kapasitelerine sahip betonarme elemanların kullanılması patlama etkilerinin azaltılmasında etkili olacaktır. Bu duruma ilişkin ve Şekil 1-b'de de patlama bölgesinde bulunan yapıların tamamen göçmesine karşın betonarme siloların ayakta kalmış olması patlama etkilerinde betonarme elemanların etkisini göz önüne sermektedir. 


\section{Kaynaklar}

[1] Toplu E., 2020, Sismik Yalıtımlı Yapılarda Patlama Etkilerinin Incelenmesi ,Sakarya Üniversitesi FBE, Yüksek lisans tezi

[2] Url-1< https://www.aa.com.tr >,

[3] Url-2 < https://commons.wikimedia.org/w/index.php?curid=92996957 >

[4] Cömert, M . (2010). Betonarme Yapıların Patlamalar Karşısındaki Performanslarının Değerlendirilmesi (Doctoral dissertation, Fen Bilimleri Enstitüsü).

[5] Wang, W., Zhang, D., Lu, F., Wang, S. C., \& Tang, F. (2012). Experimental study on scaling the explosion resistance of a one-way square reinforced concrete slab under a close-in blast loading. International Journal of Impact Engineering, 49, 158-164.

[6] Liu, Y., Yan, J. B., \& Huang, F. L. (2018). Behavior of reinforced concrete beams and columns subjected to blast loading. Defence Technology, 14(5), 550-559.

[7] Gram, M. M., Clark, A. J., Hegemier, G. A., \& Seible, F. (2012). Laboratory simulation of blast loading on building and bridge structures. WIT Transactions on State-of-the-art in Science and Engineering, 60.

[8] Fujikura, S., Bruneau, M., \& Lopez-Garcia, D. (2008). Experimental investigation of multihazard resistant bridge piers having concrete-filled steel tube under blast loading. Journal of Bridge Engineering, 13(6), 586-594.

[9] Maji, A. K., Brown, J. P., \& Urgessa, G. S. (2008). Full-scale testing and analysis for blastresistant design. Journal of Aerospace Engineering, 21(4), 217-225.

[10] ASCE (2010) Petrochemical, Design of Blast-resistant Buildings in Petrochemical Facilities. Task Committee on Blast-Resistant Design of the Petrochemical Committee of the Energy Division. Second edition.

[11] Rey, V., Gálvez, F., Sancho, R., \& Cendón, D. A. (2018). Experimental Procedure for ASCE. Testing Concrete Slabs Under Blast Loading. Multidisciplinary Digital Publishing Institute Proceedings (Vol. 2, No. 8, p. 459).

[12] Url-3<http://www.ludre.com.tr>

[13] Clancey VJ (1972) Diagnostic features of explosion damage. In: Paper presented at the sixthinternational meeting of forensic sciences, Edinburgh

[14] FEMA. (2003). Primer for Design of Commercial Buildings to Mitigate Terrorist Attacks. FEMA 427.

[15] Baker W.E., (1973) "Explosions in Air”, Univ. of Texas Press, Austin TX USA.

[16] TBDY (2018), Afet ve Acil Durum Yönetimi Başkanlığı, Ankara, https://www.afad.gov.tr/tr/24210/Turkiye-Bina-Deprem-Yonetmeligi 